\title{
The Most Common Diseases among Syrian and Palestinian Refugees to Lebanon: Acute and Chronic Stress Related Diseases are Prevalent
}

J. Suvada (Jozef Suvada)',2, I. Beldjebel (Irad Beldjebel)' , V. Krcmery (Vladimir Krcmery)2, Z. Dudova (Zuzana Dudova)', L. Ulmann (Premyslaw Ulman)1,3, A. Mamova (Alexandra Mamova)2, M. Leisten (Michael Leisten)2, M. Nachtmanova (Michaela Nachtmanova)2), L. Kovacova (Lenka Kovacova)2, A. Kunikova (Andrea Kunikova)² andP. Czarneczki (Pawel Czarnecki)2,4

Original Article

1 St. Charles Foucauld Clinic UNHCR - IV, Dbayeh, Beirut, LB

2 St. Elisabeth PhD Program Bratislava, SK

${ }^{3}$ Step In and Univ. (SEUC) Program in Erbil ,Autonom.Rep of Kurdistan, IQ

${ }^{4}$ University of Management, Warszaw, PL

\section{E-mail address:}

jose.suvada@gmail.com

\section{Reprint address:}

Jozef Suvada, M.D., PhD.

St. Charles de Foucault Center

Beirut

LB

Suource: Clinical Social Work and Health Intervention

Pages: $50-53$
Volume: 8

Cited references: 4

Issue: 1

\section{Reviewers:}

Daniel J. West, Jr. Ph.D, FACHE

University of Scranton

Department of Health Administration and Human Resources, USA

Roberto Cauda, Ph.D., MD

Institute of Infectious Diseases

Catholic University of the Sacred Heart, Rome, IT

\section{Key words:}

Refugees, Vulnerable populations,Infectious diseases.

\section{Publisher:}

International Society of Applied Preventive Medicine i-gap

CSWHI 2017; 8(1): 50 - 53; DOI 10.22359/cswhi_8_1_11 @ 2017 Clinical Social Work and Health Intervention 


\section{Abstract:}

The authors share observations on a cohort of two groups of refugees and show differences between acute and chronic stress and infectious diseases among three generations of Palestinians ( $1{ }^{\text {st }}$ Group) compared with Syrian, Iraqi and Afghanistan ( $2^{\text {nd }}$ Group) refugees migrating to Lebanon. We highlight acute risk factors for these pathologies among different groups of migrants, as well.

Lifestyle factors, together with lack of public health services, preventive medicine and access to free healthcare predispose some to specific diseases such as diabetes and hypertension. Hereditary factors are sometimes important, too, as in sickle cell disease, thalassemia and glucose-6-phosphate dehydrogenase deficiency. A minority of Outpatients presented malnutrition, intestinal parasites (Enterobius, Trichuris, Strongyloides and Ascaris), filariasis, leishmaniasis, hepatitis A, B and $\mathrm{C}$, tuberculosis, low immunization rate, typhoid fever, yellow fever, malaria, trachoma, syphilis, dengue fever, HIV infection, diarrheal diseases, leprosy, and other communicable diseases which represent less than $30 \%$ of all outpatient visits.

Syrian and Palestinian immigrants and refugees have arrived to Lebanon from diverse social, economic, educational, cultural and religious backgrounds for a variety of reasons: to seek work, education, economic advantage or to flee war, political upheaval or persecution or join families from which they have been separated. Many of them have arrived with inadequate resources and suffer social exclusion and inequality of healthcare access. The acute phase following immigration, particularly from the war zones is the time when health can be neglected. They come from healthcare systems that differ from traditional Western medicine, often may involve traditional remedies and health prevention is not part of daily life due to numerous reasons among immigrating families. Stress related disorders are more prevalent than communicable diseases.

\section{Conflict of interest:}

The authors whose names are listed in the title of the article certify that they have NO affiliations with or involvement in any organization or entity with any financial interest (such as honoraria; educational grants; participation in speakers' bureaus; membership, employment, consultancies, or other equity interest), or non-financial interest (such as personal or professional relationships, affiliations, knowledge or beliefs) in the subject matter or materials discussed in this manuscript.

\section{Introduction}

Syrian and Palestinian immigrants and refugees have arrived to Lebanon from diverse social, economic, educational, cultural and religious backgrounds for a variety of reasons: to seek work, education, economic advantage or to flee war, political upheaval or persecution or to join families from 
whom they have been separated. Many of them have arrived with inadequate resources and suffer social exclusion and inequality of healthcare access (1-2). The acute phase following immigration, particularly from the war zones is the time when health can be neglected. Migrants come from healthcare systems that differ from traditional Western medicine, often may involve traditional remedies and health prevention is not part of daily life due to numerous reasons among immigrating families. Stress related disorders such as post-traumatic stress disorders (PTSD) are prevalent in contrast to communicable diseases: 2-3 to 1 (3-4).

\section{Patients and Methods}

The St. Charles Foucauld Clinic has two Departments (OPD) and a mobile team visiting families of refugees displaced in the urban area of North Bein or reside at the UNHCR Dbayeh Camp. The population of this camp is about 10,000 and is composed of three generations of Palestinian refugees $(50-60 \%)$ plus new refugees from Iraq (2012) and Syria (2014-2017). Two doctors and two nurses and full local staff (Lab Technicians, Pharmacist, etc.) offer an OPD $6 \mathrm{x}$ week.

\section{Results and Discussion}

As social determinants of health patients visiting our St. Charles Foucauld OPD in the UNHCR Camp presented acute phase hypertension, coronary disease, diabetes, depression, gastrointestinal problems (e.g. lactose intolerance, non-organic abdominal pain), carcinomas of the cervix, breast, colon and mouth. They also suffered from vitamin D deficiency and such social pathologies as alcoholism and substance abuse.

The second phase, transition, typically takes at least 5 to 8 years, with acculturation and modification of social norms, attitudes, values, behaviors and diet; bringing changes not least in the use of health-care services even if in similar ethnic regions as the Near East and Middle East. Most youth and young adults become well integrated into their communities as they adapt to the social environment in Lebanon. But, there is still remaining daily or occasional stress from family (e.g. social insecurity, no money to pay for admission into the hospital, or option to diagnose and then to treat serious diagnoses among family members as cancer, failure of the kidneys, inherited diseases or mental diseases).

The third phase, 10 or more years after arrival, is typified by the resettled refugees presenting a variety of chronic conditions, seen at least partly as a consequence of resettlement; but in a multicultural society many have acculturated while others continue to live and often work in their own communities. In our work, we share observations from a 5 years treated cohort of refugees and we show differences between acute and chronic stress, and infectious diseases among immigrants from Palestine and Syria to Lebanon; and we highlight risk factors for these conditions among different age groups, as well.

\section{Conclusions}

PTSD and other stress related disorders are common in migrant and refugee population and aggravate such chronic conditions as asthma, cardiovascular diseases, diabetes, psychological and psychiatric disorders. Despite the fact that the majority of refugees in Lebanon originated from Syria, Iraq and Afghanistan, all war zones, infectious diseases are rare. Chronic diseases and conditions worsened by stress, hypertension, coronary heart disease, diabetes and asthma, should be screened as well as infectious diseases. 


\section{References}

1. PRESTILEO T, Di LORENZE F, Corrao S: (2015) Infectious Diseases among African irregular migrants in Italy. Just an individual problem? Clin.Soc.Work, 5, 45

2. ESCOBIO FA, ECHEVARRIA J, RUBAKI S, VINICZAI V (2015) Health assistance of displaced people along the Balkan Route, The Lancet, 386, Dec.19, 2475
3. WICZMANDYOVA D, TKACOVA, L, MURGOVA, M: Proceedings Slovak Med. Univ.: The Socio Economic Aspect of Migrations, ISBN 978-80-89352-47-0, pp.62-70

4. DUDOVA Z et al. (2016) Six month follow-up in communicable versus non-communicable diseases in an Iraqi refugee camp, Clinical Social Work and Health Intervention Vol. 7 No. 3 